\title{
Utilizing Facebook and Messenger Groups as Platforms for Delivering Mathematics Interventions in Modular Distance Learning
}

\author{
Alvin Odon Insorio ${ }^{1,2,3 *}$ [D, Jocelynda Almendrala Olivarez ${ }^{3}$ (두
}

\author{
${ }^{1}$ College of Graduate Studies and Teacher Education Research, Philippine Normal University, PHILIPPINES \\ ${ }^{2}$ San Pedro College of Business Administration, PHILIPPINES \\ ${ }^{3}$ San Pedro Relocation Center National High School - Main Campus, PHILIPPINES \\ *Corresponding Author: alvininsorio0413@gmail.com
}

Citation: Insorio, A. O., \& Olivarez, J. A. (2021). Utilizing Facebook and Messenger Groups as Platforms for Delivering Mathematics Interventions in Modular Distance Learning. International Journal of Professional Development, Learners and Learning, 3(1), ep2109. https://doi.org/10.30935/ijpdll/11290

\begin{abstract}
Modular distance learning is the most implemented learning delivery modality in the Philippines, wherein students learn the lessons through the help of self-learning modules. However, students struggle to learn mathematics lessons independently under this modality based on summative tests and performance tasks' results from the first grading period using self-learning modules. So, interventions must be placed by using social media platforms preferred by most of the students to reach and help them. The study aimed to assess the utilization of Facebook and Messenger groups as platforms for delivering video lessons and activities, learning materials, administering the test, and answering queries of the students in grade 9 Mathematics following the modified PDSA model. The study employed a practical action research design utilizing surveys, interviews, and test materials as data collection methods validated by master teachers and a head teacher. The pretest was administered before two months of interventions. After that, the posttest, survey, and interview were administered. Based on the results, the pretest scores are statistically different from the posttest scores. It means the interventions via Facebook and Messenger groups help students cope with modular distance learning challenges. The interventions done by the teacher were effective based on the computed effect size so that the students able to learn mathematics competencies despite having in the comfort of their houses. As a result, students better understand the mathematics lessons and enjoy learning at their own pace.
\end{abstract}

Keywords: Facebook, mathematics intervention, Messenger groups, modular distance learning

Received: 12 May $2021 \bullet$ Accepted: 6 Sep. 2021

\section{INTRODUCTION}

Modular distance learning is the most implemented learning delivery modality for students in the Philippines in the new normal setting. Self-learning modules are given to the students quarterly to continue self-paced learning while staying at home. This modality pertains to individualized instruction wherein the student uses selflearning modules and other learning materials with less interaction with the teachers (DepEd Order No. 012 s. 2020). However, the teacher's responsibility under this modality is to monitor the student's progress. The student may ask the teacher for assistance in any means like email, text message, instant messaging, call, or even home visitation. Moreover, any family member or stakeholder in the community may be served as a para-teacher to assist the learning needs.

In modular distance learning, students are autonomous and agents to take charge of their learning individually. They develop a sense of responsibility since the tasks on the modules are self-paced. However, teachers must assess the student's learning needs, make appropriate interventions, and use available local resources in the form of online (Labrado et al., 2020). Since self-paced learning does not guarantee the mastery of the most essential learning competencies (MELC) that the DepEd prescribed, teachers must find ways to reach the students and develop their capabilities of understanding the lesson in Mathematics.

Dangle and Sumaoang (2020) revealed the challenges experienced in implementing modular distance learning in two public secondary schools in the Philippines. These were insufficient funds for the production and delivery of self-learning modules. As a result, students struggled with self-paced learning modules, and parents do not know how to guide their children academically. They concluded that aside from text and call, social media like Facebook Messenger was the most practical mode of communication among teachers, students, and parents. Teachers must be active online and patient enough to cater to the students' and parents' learning needs and sentiments. This supports the utilization of social media platforms for modular distance learning. 


\section{LITERATURE REVIEW}

Facebook and Messenger are well-known social network sites used by many students daily (Kirschner \& Karpinski, 2010; O’Brien, 2011; Ophus \& Abbitt, 2009). These have greater potentials for the teachinglearning process as a learning management system (Wang et al., 2011) because they promote interaction among the students and teachers (Lonn \& Teasley, 2009; West et al., 2007). Facebook can be used to share learning materials like videos, pictures, PowerPoint presentations, voice clips, files, and websites; follow people or daily news that support collaborative learning, and provides a question and answer mechanism (Gülbahar et al., 2010). They enable collaborative learning, sharing of resources and learning materials, develops critical thinking and communicative skills, develops writing skills, provides active participation, and creates a positive attitude towards learning (Ajjan \& Harsthone, 2008; Bosch, 2009; Özmen et al., 2011; Ractham \& Firpo, 2011; Yuen \& Yuen, 2008).

Ooi and Loh (2010) utilized the Facebook group for a secondary Chinese language class. They noticed that Facebook was an excellent avenue to share learning resources and giving comments. It also allowed the teacher to organize learning activities conveniently. However, the students must sense safety, security, and comfort when using the said social media (Karahasanovic et al., 2009). This guarantees the effectiveness of social media utilization as educational platforms, especially in crisis time, since the students widely use these for socialization, communications, and sharing of resources with other students. Also, Moran et al. (2011) concluded in their study that students were more comfortable using Facebook for educational purposes rather than teachers because they were more preferred to use conventional communication technology, such as email, call, or text.

Wang et al. (2011) conducted an exploratory study utilizing the Facebook groups as learning management systems through a survey of students' perceptions. They found that Facebook allows the teacher and students to post announcements, share resources, conduct online discussions, and join weekly activities. Moreover, it gives control to the teachers compared with the commercial learning management system. Similarly, Meishar-Tal et al. (2012) concluded that students were satisfied with their learning using Facebook, and they liked to continue using Facebook groups for future learning areas. However, using Facebook was more suited to young learners since they were digital natives willing to adopt new technology than matured learners (Vodanovich et al., 2010).

Menon (2012) investigated the use of Facebook groups in medical education and found that Facebook groups were helpful to engage the students in learning that stimulates the student's creative thinking. Hence, it was supported by the study of Pellizzari (2012) showed that Facebook groups improved the qualitative part of the mathematics performance of the students. Kurtz (2014) concluded that Facebook groups were considered safe platforms for the students' social learning and participation, an avenue for active interactions and contributions of the students with peers and teachers, and ways to reach the students. Pai et al. (2017) found in their study that using Facebook groups to discuss a scientific argument they like to debate surpassed teachers' expectations. Students actively joined the discussion in the post and comments in Facebook groups to feel free to give their opinion and stance. Giannikas (2020) revealed that students were favorable to
Facebook groups as alternative learning management systems (LMS) which were convenient and interactive for learning.

Kalelioğlu (2017) argued that Facebook could be used for the learning areas that need sharing of lecture notes and video lessons, cloud-based applications for computation, posting the link to assignments, synchronous and asynchronous communication, posting an announcement, and when the class size is small. This supports the use of Facebook as a vehicle to deliver mathematics intervention for the students under modular distance learning to reach, communicate, assist, ask for feedback and monitor students' learning. However, the distractions caused by notifications, advertisements, games, and other online friends are common problems that the students need to control while using Facebook. Therefore, it is up to the students to deal with distractions while consuming the mathematics interventions beyond the present study's scope.

Anggoro and Rueangrong (2020) conducted a study on Facebook as an alternative learning platform for online learning in the COVID19 pandemic time. They concluded that this platform can be utilized as a reliable learning management system capable of sharing and storing different files, synchronous and asynchronous interaction, monitoring students' outputs, and giving feedback. This platform supports students' active learning (Akbari et al., 2016; Kabilan et al., 2010), thus making them more engaged. It means Facebook can be used for educational purposes for successful remote teaching (Allen, 2012; Kent \& Leaver, 2014; Towner \& Munoz, 2011; Anggoro \& Rueangrong, 2020). It has a closed group feature to make file sharing and communicating secure, confidential and only members can see the content and people within the group. However, the educational application of Facebook may be uplifted if it is used in meaningful ways (Celik et al., 2015; Mazman \& Usluel, 2010). It means Facebook must be utilized thoroughly for educational purposes only to benefit both teachers and students.

Social media has been proven in many studies that facilitate educational activities through collaboration, interaction, active participation, critical thinking, and learning content sharing (Choi, 2013; Thoms \& Eryilmaz, 2014). Niu (2017) argued that Facebook as social media could be used as a learning management system (LMS); however, the effect of Facebook as an LMS has been understudied, even though many experts recommended the integration of Facebook in teaching and learning. It is better to investigate the effect of Facebook as LMS to explore its maximum benefits aside from entertainment and communication. The informal and formal communication practices via Facebook enhance learning and maintain students' interest (Dohn \& Dohn, 2017). The statements above justify the research gap about the effect of Facebook as a platform to reach and teach students in a distant manner. These ignite the need to conduct a study to verify if Facebook can be used as LMS.

Meanwhile, Facebook Messenger is the number one messaging application in 64 countries (Bobrov, 2018) due to the advanced features that users like and need (Dogtiev, 2018). The said platform is mainly used by the students rather than email or mobile phones during academic consultations due to its convenience to use (Tananuraksakul, 2018). It can share various media types, create group chats, send voice clips and text messages, and make audio and video calls (Gangneux, 2020). It was released as a stand-alone application of Facebook in 2011. Moreover, it can be used as an online discussion platform to improve the students' responses to test performance (Farhan, 2019). Therefore, it is conducive to use since most of the students have an active Facebook 
account, and they are more familiar with using this application. Moreover, Messenger's instant messaging feature makes this application advantageous with other online platforms even without an internet connection as long as the mobile phone data is opened.

Tananuraksakul (2018) investigated Facebook Messenger as a medium of academic consultation of teachers to students. He concluded that students have a positive attitude towards Facebook Messenger as a medium of academic discussion that positively affects body and mind with confidence, convenience, less travel time, and saving money. Furthermore, he added that Facebook Messenger could be used as a medium of academic learning since the students are digital natives. This supports the present study's claim that Facebook Messenger is the easiest way to communicate with the students.

Related studies have been conducted regarding the utilization of Facebook and social networks concerning students' academic performance (Wang et al., 2011) were done before the pandemic Facebook as a platform in delivering the lessons has been reported to enhance students' achievement and engagement (Akbari et al., 2016; Kalelioğlu, 2017; Samani \& Noordin, 2020). Hence, platforms for online instruction that facilitate active learning is needed to investigate (Anggoro \& Rueangrong, 2020). However, no study has been conducted on utilizing Facebook and Messenger groups to deliver mathematics interventions for the students under a modular distance learning modality in the new normal situation wherein face-to-face classes are not permitted.

In modular distance learning, students learn at their own pace with less assistance from the teachers. Moreover, few studies have been conducted regarding the teaching-learning process in modular distance learning, particularly in mathematics subjects. Furthermore, the implementation of modular distance learning brings challenges to students' learning and teachers' instruction (Castroverde \& Acala, 2021). The above research gap motivates the researchers to continue conducting action research since it aligns with the Basic Education Learning Continuity Plan (BE-LCP) of the school where the study was conducted. Moreover, DepEd Order No. 012 s. 2020 stated that the research priority for the school year 2020-2021 must be aligned with the BE-LCP of the school. Hence, Özmen and Atıcı (2014) claimed that distance learning activities create positive learning outcomes when social networks are integrated wherein learners learn more.

\section{Theoretical and Conceptual Framework}

The study utilized the Facebook and Messenger groups as platforms for delivering mathematics interventions such as posting video lessons and activities, additional learning materials, communicating with the students, administering the summative tests, and answering the students' queries. The students commonly used these platforms due to their convenience, requiring less consumption on internet bandwidth as long as a device is available. Hence, most of the students have mobile phones on their own, social media is easy and convenient for them. Moreover, grade 9 students aged 15 or above have a Facebook account used for socialization with friends and classmates. Therefore, they have access to the said social media that require less internet consumption, while Messenger can be used even without an internet connection.

The mathematics teacher created MELC aligned teacher-made video lessons using their smartphones and additional learning materials uploaded to Facebook and Messenger groups. The said groups were exclusive to the students and mathematics teacher to have the confidentiality of the content. The students were instructed to post a heart shape after watching the video lessons and answer the activity posted after the video through a personal message to secure their answers' confidentiality. Similarly, the summative assessment was posted every four weeks to assess the learning outcomes and elicit feedback on the interventions. The students can submit the answer via Messenger or write on a paper sheet and be submitted in school. Through the Messenger group's use, the students may ask the teacher questions/clarifications regarding the lesson to address these challenges immediately. Moreover, communication was done quickly through Messenger groups, even personal messages if the students preferred it.

The study was carried on in San Pedro Relocation Center National High School - Main campus for the school year 2020-2021, located at Old Tenant Imelda Avenue Langgam, San Pedro City, Laguna, Philippines. It is a public school offering junior and senior high school catering 5, 800 students under modular distance learning modality committed to delivering quality and accessible education, despite the pandemic's challenges through school learning continuity plan. In addition, the school prioritizes students, teachers, and staff's welfare, health, safety, and well-being and strives to continue delivering quality basic education.

It has been highly observed that the students were struggling in new normal learning situations wherein they stay at home studying the selflearning modules with less assistance from their teachers. The modules' contents were not enough to fully understand the concepts and develop the target most essential learning competencies, especially in mathematics, wherein lessons were abstract, requiring teachers' guidance even if they have parents or guardians beside them. Moreover, the mathematics module topics were not simplified with fewer examples and explanations; some instructions were hard-to-understand for the students, and learning competencies were hard-to-develop alone based on the result of the initial survey.

It has been observed from the first quarter of the school year 20202021; students were struggling in learning the mathematics competencies in grade 9 , as seen on the result of the summative test and performance task. The mastery of the competencies was superficial, requiring teacher's interventions to understand the mathematical concepts in every lesson thoroughly. In addition, challenges arose for the students on how to learn mathematics concepts independently. To address the perceived problems, mathematics teachers tried to find ways to deliver quality mathematics education despite modular distance learning challenges. Through consultation with other mathematics teachers, a head teacher, and students, Facebook and Messenger groups were the most feasible platforms for reaching the students since these were commonly used by the students in public schools. Moreover, the interventions must be made by the mathematics teachers not taken from many resources on the internet like Youtube recorded video to ensure that the content was aligned to the module. Unfortunately, the self-learning module was not available early for the 3rd quarter.

Figure 1 shows the modified PDSA model of conducting action research based on the local context. It has four stages: planning, doing, studying, and acting with the teacher's activity and student's participation across the stages. Each stage has four processes that contribute to the development of the whole study. Each process involves the teacher's activity in executing steps with students participation following the nature of action research. Proper protocols at the start of the study, such as faculty meetings, permission from the 


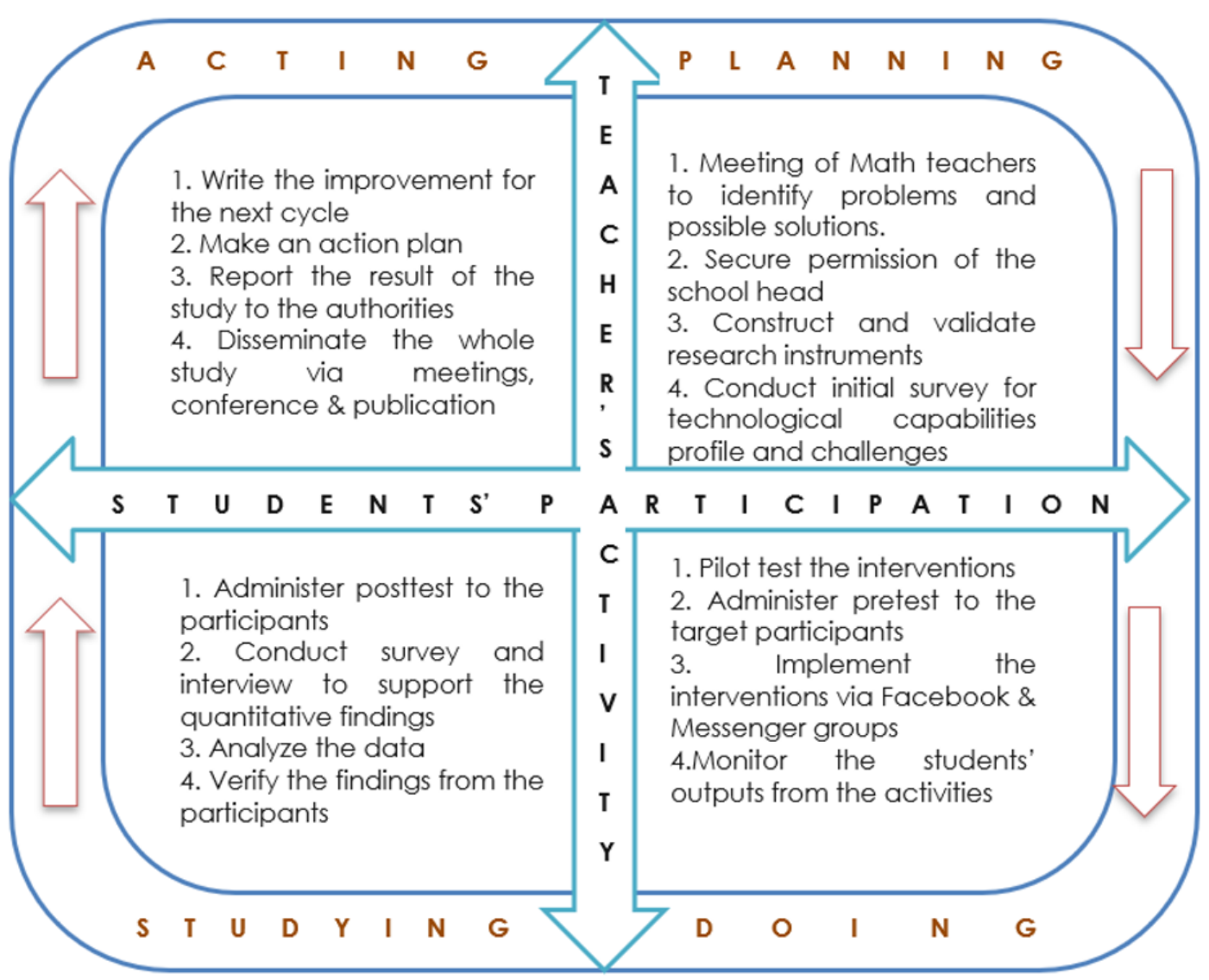

Figure 1. Conceptual paradigm

authority, construction and validation of instruments, and the conduct of the initial survey, were carried out. Students' profiling in terms of the device at home and internet connection was considered to determine their technological capabilities and challenges in modular distance learning. Pilot testing of the interventions was held for two weeks and students' suggestions were elicited to improve the implementation process, like having more videos in Tagalog-English explanation. By considering the most essential learning competencies, consultative meetings, and technological capabilities, mathematics interventions such as video lessons and activities, learning materials, assessment, and communication via Facebook and Messenger groups were administered for two months. A 30-item pretest was administered to measure the students' prior knowledge in the $3^{\text {rd }}$ grading period in grade 9 mathematics. After the two-month implementation, a posttest was administered parallel to the pretest material. The effect of interventions on understanding mathematics lessons and students' suggestions to improve the effectiveness of platforms in delivering the interventions were elicited through interviews and surveys. After collecting data, the analysis was followed, and verification of findings to ensure their veracity. Reporting and disseminating the study result were done as part of the action plan for the next action research cycle.

\section{Research Questions}

This study aimed to assess Facebook and Messenger groups' utilization as platforms for delivering mathematics interventions for the students. Mainly, it searched to respond to the following questions: 1. What are the mean scores of students in the pretest and the posttest examination? 2. Is there a statistical difference in the mean scores of pretest and posttest? 3. What are the effects of interventions via Facebook and Messenger groups in helping the student to understand the mathematics lesson better? 4. What are the students' suggestions to improve Facebook and Messenger groups' utilization in delivering the interventions?

\section{METHODOLOGY}

\section{Research Design and Participants}

The study utilized a practical action design focusing on using Facebook and Messenger groups in delivering Mathematics interventions for modular distance learning in grade 9. A practical action research design is intended to solve a particular problem to improve people's practices in the short term (Fraenkel \& Wallen, 2010). Since the study intended to solve immediate problems in learning mathematics competencies in modular distance learning, practical action was the best method to execute. On the other hand, the participants came from four sections of grade 9 who struggled with mathematics lessons, as seen from the previous summative tests' results and performance tasks. A total of 120 students participated voluntarily, but with internet access and device. Therefore, purposive sampling was employed in the selection of sections of participants. The study was carried on in San Pedro Relocation Center National High School - Main Campus for the academic year 2020-2021. The said school implemented modular distance learning through self-learning modules given to the students quarterly. However, modules did not arrive timely from publications, and the contents were not easy to understand. So, the teacher made ways to help the students to develop mathematical competencies utilizing the available resources. 


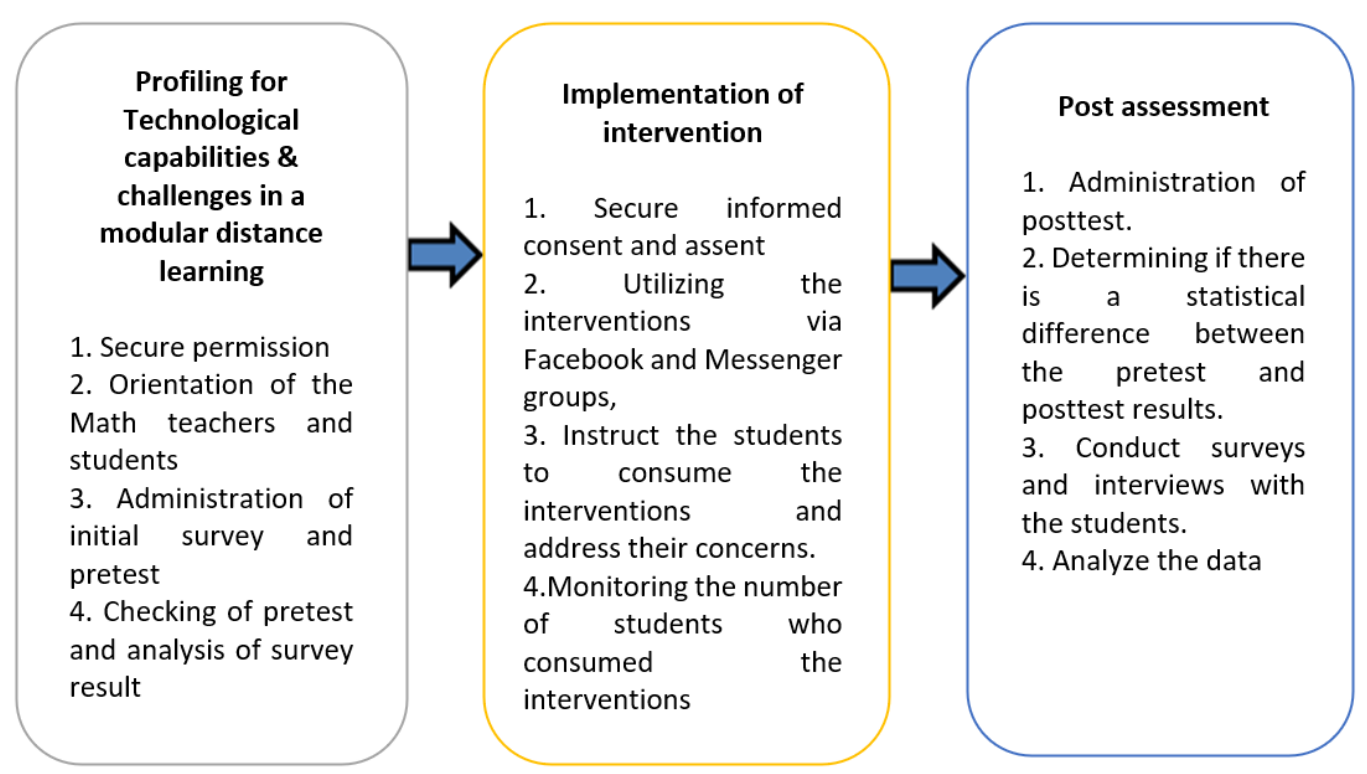

Figure 2. Flow chart of data gathering procedure in three stages

\section{Research Instruments}

The first instrument in this study was the ten-item initial survey questionnaire validated by the mathematics head teacher for the profiling of students to determine the technological capabilities and challenges in modular distance learning of the students via Messenger groups. Items regarding internet connection, device ownership, frequency of using Facebook and Messenger, difficulties experienced in modular distance learning, preferred language for video lesson, and assistance needed by the students were included in the first instrument. It took two weeks to collect data as the basis of crafting interventions. The second instrument was the 30 -item selected-response pretest and another 30-item parallel posttest based on the most essential learning competencies for the 3rd quarter. Two master teachers and one head teacher in the mathematics department validated the said instruments in terms of format and design, content, clarity, and usefulness. Their suggestions were strictly followed, and the revised version was returned for their approval to use the test material. Pilot-testing to nonparticipants was administered for the reliability index using KuderRichardson Formula 20 since the test materials were composed of $60 \%$ easy, $30 \%$ average, and $10 \%$ difficult. The reliability indices are .81 and .84 , respectively. These justified the validity and reliability of test materials. On the other hand, the third instrument was the five-item open-ended survey via a poll to elicit the effect of interventions and suggestions for improving the utilization of Facebook and Messenger groups as platforms. The third instrument was validated also by the two master teachers and one head teacher in terms of the content based on the objectives of the study. The first draft was eight items, but due to the suggestions of the validators, it was trimmed down to five items and rephrased three times before its use. Moreover, informal interviews for twenty participants were conducted to verify and clarify the students' answers to the survey via video chat or call. The interview lasts for 15 -30 minutes.

\section{Data Gathering Procedure}

Figure 2 shows the data gathering procedure from the preimplementation to the post-implementation stage. The preimplementation stage started with securing permission from the school head up to collect the initial data. Based on the data, $95 \%$ of the students from grade 9 have internet access via data load or fiber connection. Of which, $91 \%$ have smartphones, $5 \%$ have laptops, and $4 \%$ have tablets owned by the students or parents. Also, $99 \%$ of them were Facebook users. These justify the possible realization for the delivery of the mathematics interventions. The implementation stage started from securing consent to monitor the students on consuming interventions to decide if the teacher must continue the interventions or not. Finally, the post-implementation started from the posttest administration to data analysis. Quantitative data were treated using SPSS version 23, while qualitative data in thematic analysis through manual coding.

Permission from the school head was secured by writing a formal letter signed by the Mathematics department head as part of the protocol. After the grant of permission, orientation with the mathematics teachers and students was held to inform the study's procedure via video. An initial survey was administered to determine the students' technological capabilities regarding device ownership and internet connections and challenges in modular distance learning to put considerations and adjustments on priorities. Similarly, a 30-item pretest was administered via Messenger groups for one day by posting the test items. At the same time, the answer was sent through a personal message to secure the confidentiality of the answers. If the students do not have internet access, they may message the teacher to give a data load on that day. The teacher checked a pretest, and data analysis from the initial survey was done immediately.

From the initial survey results, the researchers identified the possible interventions considering the students' availability, technological capabilities, the module's content, most essential learning competencies, and the nature of learners as Millenials. Before the implementation stage, the informed consent and assent form was sent to the students during the module's distribution since the participants were minors aged between 14 to 18 years old. In addition, interventions in video lessons, additional learning materials, follow-up activities, communications, and surveys were posted via Facebook and Messenger groups. Finally, the interventions were implemented for two months under the $3^{\text {rd }}$ grading period via Facebook and Messenger groups. The mathematics teacher monitored the number of students who consumed the interventions and made announcements to inform the students. 
Table 1. One-sample Kolmogorov-Smirnov test to determine the normality of data

\begin{tabular}{|c|c|c|c|c|c|c|c|c|c|}
\hline \multicolumn{2}{|c|}{ Statistics } & \multicolumn{4}{|c|}{ Pretest } & \multicolumn{4}{|c|}{ Posttest } \\
\hline & & $\mathbf{A}$ & $\mathbf{B}$ & $\mathbf{C}$ & $\mathbf{D}$ & $\mathbf{A}$ & $\mathbf{B}$ & $\mathbf{C}$ & $\mathbf{D}$ \\
\hline \multicolumn{2}{|c|}{$\mathrm{N}$} & 30 & 30 & 30 & 30 & 30 & 30 & 30 & 30 \\
\hline \multirow{2}{*}{ Normal Parameters ${ }^{\mathrm{a}, \mathrm{b}}$} & Mean & 9.40 & 10.73 & 10.40 & 10.00 & 23.17 & 23.43 & 23.67 & 22.83 \\
\hline & Std. Deviation & 2.61 & 3.48 & 3.22 & 1.72 & 3.06 & 2.49 & 2.64 & 3.14 \\
\hline \multirow{3}{*}{$\begin{array}{c}\text { Most Extreme } \\
\text { Differences }\end{array}$} & Absolute & .128 & .158 & .149 & .133 & .159 & .136 & .145 & .116 \\
\hline & Positive & .128 & .158 & .149 & .133 & .159 & .136 & .145 & .116 \\
\hline & Negative & .128 & .158 & .149 & .133 & .116 & .116 & .100 & .116 \\
\hline \multicolumn{2}{|c|}{ Test Statistic } & .128 & .158 & .149 & .133 & .159 & .136 & .145 & .116 \\
\hline \multicolumn{2}{|c|}{ Asymp. Sig. (2-tailed) } & $.200^{\mathrm{c}, \mathrm{d}}$ & $.054^{\mathrm{c}}$ & $.086^{\mathrm{c}}$ & $.183^{\mathrm{c}}$ & $.052^{\mathrm{c}}$ & $.167^{\mathrm{c}}$ & $.110^{\mathrm{c}}$ & $.200^{\mathrm{c}, \mathrm{d}}$ \\
\hline
\end{tabular}

Instruction of the follow-up activities was given, and the students must answer the activities as proof of consuming interventions. Students were asked to post a heart shape on the video lesson as a sign they watched. Random messaging was conducted to check the students' understanding and get suggestions to improve the interventions. For post-implementation, a posttest was administered after two months to assess the learning outcomes by identifying significant differences in pretest and posttest scores. Surveys and interviews were administered to determine the effect of the students' interventions and suggestions to improve the utilization of Facebook and Messenger groups as platforms.

\section{Data Analysis}

Quantitative data were measured in the ratio level of measurement in terms of scores, so mean, standard deviation, and KolmogorovSmirnov test were the descriptive statistics applicable to describe the data. However, paired sample t-test, Cohen's d, and percentage change were appropriate tests for the statistical and practical significance of the interventions used in the study via Facebook and Messenger groups. For qualitative data, manual coding was done by repeatedly reading transcripts from the interview and poll survey and highlighting the main ideas/concepts. Then, thematic analysis was used to arrive at the different themes based on the participants' responses through reducing the data into codes, categorizing, summarizing, and reconstructing to capture the important concepts or constructs. Thematics analysis is a qualitative data reduction and strategy that search for patterns of experience to produce descriptions as themes (Given, 2008). Then, member checking was done by returning the responses to the interviewees and a summary of findings to elicit their agreement on the transcript and data analysis of qualitative data. All of the interviewees agreed on the adequacy and accuracy of the transcript and findings. Moreover, Creswell (2012) claimed that to secure the validity of qualitative data, member checking can be done by presenting the summary of findings to the interviewees by asking them about the accuracy of the transcripts and obtaining their approval to use their ideas.

Table 1 exhibits the normality test of pretest and posttest scores including the mean and standard deviation per section. Pallant (2007) said that the Kolmogorov-Smirnov (KS) test is used to test the assumption for the normality of data which is required before the use of any parametric test. The test for normality of data is required for various statistical analyses and for describing the data set (Okeniyi et al.,
2020). Based on the one-sample KS test, scores are normally distributed since the p-values are more than a .05 level of significance. Soong (2004) claimed that if the computed value in the KS test is greater than the .05 level of significance, then the data set is distributed like a normal probability distribution. By the computed p-values, it implies that the use of the parametric test for the significant difference is permissible since scores are expressed on a metric scale. The assumptions for the parametric test are satisfied. Moreover, considering the mean scores, section A got the lowest pretest mean, while section B got the highest. Unlikely, section D got the lowest posttest mean, while section $\mathrm{C}$ got the highest.

\section{Ethical Considerations}

As part of ethical considerations, the permission from the authorities and participants was secured, and data confidentiality was rest assured. The participants were informed that the data gathered from this study were stored securely on the researchers' personal computer for three years, after which all participants' identities will be erased. Their identities were not revealed throughout the study for their protection. However, an electronic summary of the findings was made available to the participants upon their request. Furthermore, the researchers were committed to share the findings of this study with high school faculty through learning action cells to discuss the significance of this study to mathematics education.

\section{RESULTS}

Table 2 shows the mean and standard deviation of pretest and posttest scores. Mean is a frequently computed measure of central tendency while standard deviation is for variability both in metric scale after the set of data has been proven normally distributed (Lydersen, 2020). Since the data set is quantitative in nature, mean and standard deviation are the best descriptive measures to describe the collected data. The pretest scores range from 3 to 19 , while the posttest scores range from 18 to 28 . It can be gleaned from the table that the mean posttest score is higher than the mean pretest score by 13.15 . Increased mean scores from the pretest to the posttest signifies that the Facebook and Messenger groups can be a learning platform to deliver interventions to improve students' performance in examinations which supports the findings of Farhan (2019). The said social media served as platforms in delivering the teacher-made learning materials

Table 2. Mean and standard deviation of pretest and posttest scores

\begin{tabular}{|c|c|c|c|c|c|c|c|}
\hline & Minimum value & Maximum value & Mean & SD & Mean difference & Cohen's d & Percentage change \\
\hline Pretest & 3 & 19 & 10.13 & 2.85 & -13.15 & 4.61 & 129.81 \\
\hline Posttest & 18 & 28 & 23.28 & 2.83 & & & \\
\hline
\end{tabular}


Table 3. Paired samples t-test for significant difference

\begin{tabular}{|c|c|c|c|c|c|c|c|c|c|}
\hline \multirow{3}{*}{\multicolumn{2}{|c|}{ Pairs }} & \multicolumn{5}{|c|}{ Paired Differences } & \multirow{3}{*}{$\mathbf{t}$} & \multirow{3}{*}{ df } & \multirow{3}{*}{ Sig. (2-tailed) } \\
\hline & & \multirow{2}{*}{ Mean } & \multirow{2}{*}{ SD } & \multirow{2}{*}{$\begin{array}{l}\text { Std. Error } \\
\text { Mean }\end{array}$} & \multicolumn{2}{|c|}{ 95\% Confidence Interval of the Difference } & & & \\
\hline & & & & & Lower & Upper & & & \\
\hline 1 & PreTest A - Posttest A & -13.767 & 3.748 & .684 & -15.166 & -12.367 & -20.119 & 29 & .000 \\
\hline 3 & Pretest C - Posttest C & -13.267 & 3.930 & .717 & -14.734 & -11.799 & -18.490 & 29 & .000 \\
\hline 4 & Pretest D - Posttest D & -12.833 & 3.630 & .663 & -14.189 & -11.478 & -19.363 & 29 & .000 \\
\hline
\end{tabular}

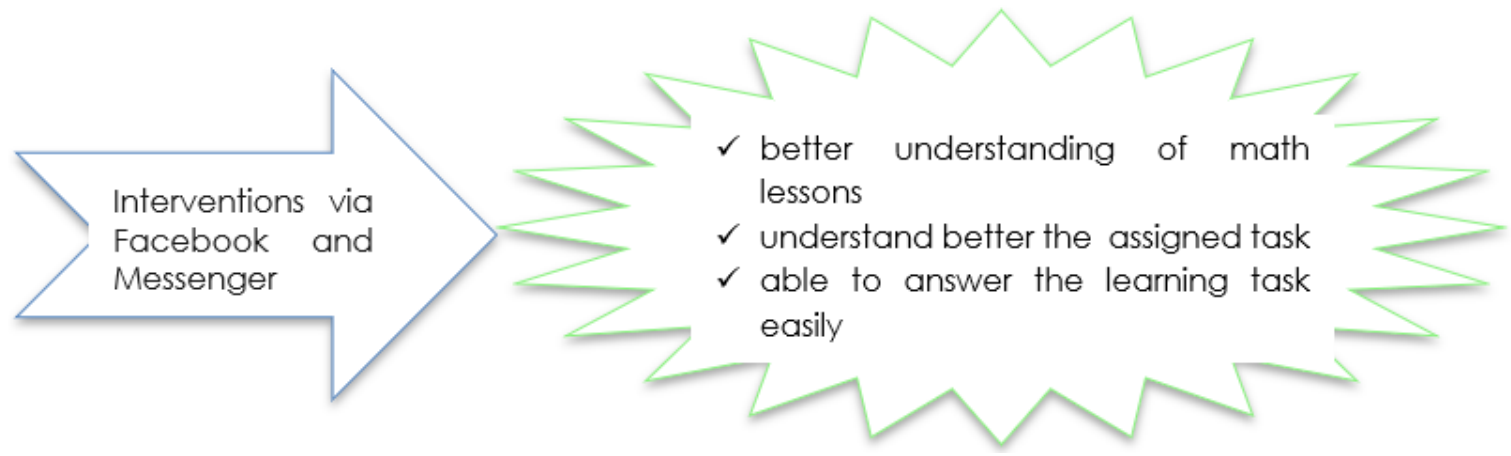

Figure 3. Effects of interventions via Facebook and Messenger groups

conveniently since many students preferred them to use in socialization, communication, and entertainment.

The effect size using Cohen's $d$ which is 4.61 that means the posttest mean score is higher than the standard deviation of the pretest scores which is better than the pretest mean score. It implies that a high effect size denotes effective interventions that must be employed again that will produce desirable outcomes. It connotes that the interventions via Facebook and Messenger groups affect the academic performance of the students in mathematics positively. Cohen's $d$ is commonly used to calculate the effect size of intervention from pretest to posttest for one group to show the practical significance after the use of a t-test (Dankel et al., 2017). Hence, the percentage change of 129.81 signifies the magnitude of the effect of the interventions derived from the formula of the difference between the pretest and posttest scores divided by the pretest score times one hundred (Clark, 2010; Hansen et al., 2011). In addition, Cohen's $d$ and percentage change are the two measures of the magnitude of the effect as a result of interventions (de Villarreal et al., 2009; de Villarreal et al., 2010).

As depicted in Table 3, a statistical difference appears between the pretest and posttest mean scores from four sections with a $\mathrm{p}$-value of .000 at 29 as a degree of freedom. It means interventions affect the performance of the students since statistical significance was established. It connotes that the interventions via Facebook and Messenger groups help the students understand the mathematics concepts, and the students could perform well academically. This justifies the effectiveness of using Facebook and Messenger groups as educational platforms for delivering teacher-made interventions in distance learning (Anggoro \& Rueangrong, 2020). Considering the mean difference, section A got the highest increment while section $B$ got the lowest. The negative sign reveals that the posttest scores are higher than in the pretest due to the interventions. The utilization of Facebook and Messenger groups enhances the mathematical understanding of the students, communication with the teacher and classmates, and learning engagement in the remote environment.

Figure 3 shows the effects of the interventions via Facebook and Messenger groups in helping the students to understand mathematics concepts. By watching the posted teacher-made video lessons and reading additional learning materials, students better understand the mathematics lessons and their assigned tasks. They found answering the activities in modules easy since they can go back repeatedly with the posted learning materials and video lessons anytime in the comfort of their houses. Even though some items on module tasks were hard to answer, consuming interventions from FB groups helps them respond to those items independently. Facebook provides active learning for the students in remote learning (Akbari et al., 2016). Students were able to develop techniques in solving mathematical problems from modules due to watching video lessons repeatedly. It implies that Facebook and Messenger can be used as platforms for delivering interventions similar to the findings of Wang et al. (2011). These platforms are easy to manage and utilize since most of the students are familiar with features and icons.

Moreover, the closed group of Facebook provides security and confidentiality of content posted by the teacher and comments posted by the students. Only the closed group members can see the student's posts and the teacher's video materials and communication. The students' performance in mathematics was enhanced through these platforms, as shown from the posttest result similar to the findings of Pellizzari (2012). Facebook as a social networking platform supports self-paced student-centered learning opportunities where the students can express their thoughts through typing comments (Samani \& Noordin, 2020). On the other hand, Messenger provides communication affordances through writing, editing, and inserting multimedia messages like voice records, pictures, emoticons, and videos. Students can ask for assistance and clarifications from the teacher personally or by group chat.

Figure 4 shows the students' suggestions to improve the utilization of Facebook and Messenger groups. First, of course, there must be a schedule of uploading of learning materials and video lessons to be aware and consume regularly. However, the teacher should notify the students in advance if he/she will upload the materials so that the students know when they use the materials since most of them are using data load to have internet access. Moreover, the teacher may conduct a 


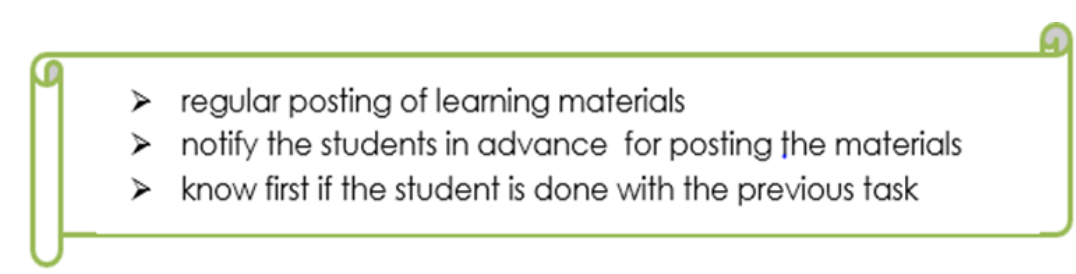

Figure 4. Student's suggestions for the improvement of Facebook and Messenger groups' utilization

poll to determine if the student is done with the previous task before uploading materials for the next lesson. This will assist the teacher in deciding if the student needs many interventions or not.

\section{DISCUSSION}

The study aimed to assess the utilization of Facebook and Messenger groups as platforms to deliver mathematics interventions such as teacher-made video lessons, activities, learning materials, communicating with the students, and administering the summative tests. The students' pretest mean scores ranged from 9.40 to 10.73 , while the posttest ranged from 22.83 to 23.67 . Based on the results, pretest scores were statistically different from posttest scores. It connotes that interventions affect the academic performance of the students. Facebook and Messenger groups as platforms were effective e-learning tools to deliver instruction, communicate with the students, administer the summative test, and address student's queries. The said platforms served as reliable learning management systems that enable storing and sharing of different files type that can facilitate remote learning (Anggoro \& Rueangrong, 2020). Moreover, Facebook as a social tool encourages the students to interact with the teacher and classmates that contribute to collaborative learning for an environment where students do not have to be in one place (Giannikas, 2020).

Through interventions via Facebook and Messenger groups, students were able to understand the mathematics lessons independently and perform learning tasks easily with less assistance from the teachers. Since the learning materials were posted, students can go again and again to clarify their thoughts and correct misconceptions regarding the lessons. Facebook and Messenger groups can be utilized as platforms for academic consultation and academic learning (Tananuraksakul, 2018). Also, these were great tools for independent learning and communicating with the students to address their learning needs. However, teachers must maintain the eagerness of the students to utilize the said platforms by the constant posting of learning materials and regular messaging the students to motivate them to work or perform the learning tasks assigned.

In the time of the global pandemic, wherein education delivery shifted to distance learning, utilizing the most preferred social media by the students in delivering the learning materials comes better than looking for any website or learning management system that requires a stable internet connection and good digital device. Facebook as a pedagogical tool for online learning improves communication and increases interactive learning even in an isolated environment (Giannikas, 2020). In the context of printed modular distance learning wherein the students do not possess a strong internet connection, utilizing Facebook and Messenger groups provides a better opportunity to reach and help the students to cope with the challenges of distance learning. However, in utilizing Facebook and Messenger as platforms, teachers should be very considerate and lenient to the situations of the students since every student comes from a diverse family background with various technological capabilities. It is better if the teacher constantly asks for feedback from the students regarding their experiences while consuming learning materials posted in Facebook or Messenger group, ask their opinions on how to improve the learning materials, and suggestions to maximize the use of the said social media for the learning delivery.

\section{CONCLUSIONS AND RECOMMENDATIONS}

The increase of mean scores from pretest to posttest shows significant findings on the utilization of Facebook and Messenger groups as platforms to deliver the interventions. Statistically, a significant difference was established. It means the interventions via Facebook and Messenger groups helped the students to perform well academically in mathematics. They understand the mathematics concepts better by consuming interventions repeatedly and answering the assigned task quickly because they know how to do the assigned activities and deal with them. However, they expected a regular posting of interventions to sustain their motivation to consume teacher-made videos and materials. Also, they suggested having advance notification if the teacher will post those materials, and the teacher may conduct a simple survey to know if the students are done with the previous tasks.

The study was limited to four sections of grade 9 in one school; it is recommended to have school-wide implementations considering the findings of this study to have improved learning outcomes. Moreover, the interventions in this study last for two months only; it is recommended for the next cycle to have a longer implementation time to see how to sustain the interventions and identify the gaps of the teacher's practices to the students' needs in modular distance learning. For the next cycle of action research, the gaps identified here will be considered to craft interventions suited to different types of students in terms of technological capabilities and interests. There should be a school-wide implementation of interventions in different subjects via Facebook and Messenger to reach and serve many students by their teachers. Moreover, similar studies may be conducted from other schools to verify the study's findings. Future researchers may conduct a study beyond the scope of the study to explore more aspects of the utilization of Facebook and Messenger groups.

Author contributions: All authors were involved in concept, design, collection of data, interpretation, writing, and critically revising the article. All authors approve final version of the article.

Funding: The authors received no financial support for the research and/or authorship of this article.

Declaration of interest: Authors declare no competing interest.

Data availability: Data generated or analysed during this study are available from the authors on request. 


\section{REFERENCES}

Ajjan, H., \& Hartshorne, R. (2008). Investigating faculty decisions to adopt Web 2.0 technologies: Theory \& empirical tests. Internet $\&$ Higher Education, 11(2), 71-80. https://doi.org/10.1016/ j.iheduc.2008.05.002

Akbari, E., Naderi, A., Simons, R. J., \& Pilot, A. (2016). Student engagement and foreign language learning through online social networks. Asian-Pacific Journal of Second and Foreign Language Education, 1(4), 1-22. https://doi.org/10.1186/s40862-016-0006-7

Allen, M. (2012). An education in Facebook. Digital Culture and Education, 4(3), 213-225. http://hdl.handle.net/20.500.11937/ 12096

Anggoro, K., \& Rueangrong, P. (2020). Facebook: An alternative learning platform for online English as a foreign language instruction in the time of COVID-19. Journal of Education Naresuan University, 23(1), 413-423. https://so06.tcithaijo.org/index.php/ edujournal_nu/article/view/244419

Bobrov, L. (2018). Mobile messaging App map - February 2018. Market Intelligence Insight. https://www.similarweb.com/blog/mobilemessaging-app-map-2018

Bosch, T. E. (2009). Using online social networking for teaching \& learning: Facebook use at the University of Cape Town. Communication: South African Journal for Communication Theory and Research, 35(2), 185-200. https://doi.org/10.1080/0250016090 3250648

Castroverde, F., \& Acala, M. (2021). Modular distance learning modality: Challenges of teachers in teaching amid the Covid-19 pandemic. International Journal of Research Studies in Education, 10 (8), 7-15. https://doi.org/10.5861/ijrse.2021.602

Celik, I., Yurt, E., \& Sahin, I. (2015). A model for understanding educational Facebook use. Eurasia Journal of Mathematics, Science \& Technology Education, 11(4), 899-907. https://doi.org/10.12973/ eurasia.2015.1447a

Choi, A. (2013). Use of Facebook group feature to promote student collaboration. American Society for Engineering Education (ASEE) Southeast Section Conference, 7.

Clark, K. P., Stearne, D. J., Walts, C. T., \& Miller, A. D. (2010). The longitudinal effects of resisted sprint training using weighted sleds vs. weighted vests. Journal of Strength and Conditioning Research, 24(12), 3287-3295. https://doi.org/10.1519/JSC.0b013e3181b62 $\mathrm{cOa}$

Creswell, J. W. (2012). Educational research: Planning, conducting, and evaluating quantitative and qualitative research (4th ed.). Pearson Education, Inc.,

Dangle, Y. R., \& Sumaoang, J. (2020). The implementation of modular distance learning in the Philippine secondary public schools. $3 \mathrm{rd}$ International Conference on Advanced Research in Teaching and Education. https://www.dpublication.com/wpcontent/uploads/ 2020/11/27-427.pdf

Dankel, S. J., Mouser, J. G., Mattocks, K. T., Counts, B. R., Jessee, M. B., Buckner, S. L., \& Loenneke, J. P. (2017). The widespread misuse of effect sizes. Journal of Science and Medicine in Sport, 20(5), 446-450. https://doi.org/10.1016/j.jsams.2016.10.003 de Villarreal, E. S. S., Requena, B., \& Newton, R. U. (2010). Does plyometric training improve strength performance? A metaanalysis. Journal of Science Medicine Sport, 13(5), 513-522. https://doi.org/10.1016/j.jsams.2009.08.005

de Villarreal, E. S.-S., Kellis, E, Kraemer, W. J., \& Izquierdo, M. (2009). Determining variables of plyometric training for improving vertical jump height performance: a meta-analysis. Journal of Strength and Conditioning Research, 23(2), 495-506. https://doi.org/10.1519/JSC.0b013e318196b7c6

DepEd Order No. 012, s. 2020. Adoption of the basic education learning continuity plan for school year 2020-2021 in the light of the covid-19 public health emergency. https://www.deped.gov.ph/wpcontent/uploads/2020/06/DO_s2020_012.pdf

Dogtiev, A. (2018). Facebook revenue and usage statistics. http://www.businessofapps.com/data/facebook-statistics/\#4

Dohn, N. B., \& Dohn, N. B. (2017). Integrating Facebook in upper secondary biology instruction: a case study of students' situational interest and participation in learning communication. Research in Science Education, 47(6), 1305-1329. https://doi.org/10.1007/ s11165-016-9549-3

Farhan, R. N. (2019). Online discussion via Facebook Messenger: Impact on students' test performance of William Golding's "Lord of the Flies." International Journal of Innovative Technology and Exploring Engineering (IJITEE), 9(2), 4782-4787. http://dx.doi.org/10.35940/ ijitee.B6702.129219

Fraenkel, J., \& Wallen, N. (2010). How to design and evaluate research in education. McGraw-Hill Companies, Inc.

Gangneux, J. (2020). Tactical agency? Young people's (dis)engagement with WhatsApp and Facebook Messenger. Convergence: The International Journal of Research into New Media Technologies, 1-14. https://doi.org/10.1177/1354856520918987

Giannikas, C. (2020). Facebook in tertiary education: The impact of social media in e-Learning, Journal of University Teaching \& Learning Practice, 17(1), 3. https://doi.org/10.53761/1.17.1.3

Given, L. (2008). The Sage encyclopedia of qualitative research methods. Sage Publications, Inc. https://doi.org/10.4135/9781412963909

Gülbahar, Y., Kalelioğlu, F., \& Madran, R.O. (2010). Sosyal ağların eğitim amaçlı kullanımı [Educational use of social networks]. inettr 2010 Internet Conference in Turkey. Istanbul, Turkey.

Hansen, K. T., Croni, J. B., Pickeringm, S. L., \& Newton, M. (2011). Does cluster loading enhance lower body power development in preseason preparation of elite rugby union players? Journal of Strength and Conditioning Research, 25(8), 2118-2126. https://doi.org/10.1519/JSC.0b013e318220b6a3

Kabilan, M. K., Ahmad, N., \& Abidin, M. J. Z. (2010). Facebook: An online environment for learning of English in institutions of higher education?. The Internet and Higher Education, 13(4), 179-187. https://doi.org/10.1016/j.iheduc.2010.07.003

Kalelioğlu, F. (2017). Using Facebook as a learning management system: Experiences of preservice teachers. Infomatics in Education, 16(1), 83-101. https://doi.org/10.15388/infedu.2017.05 
Karahasanovic, A., Brandtzæg, P. B., Heim, J., Lüders, M., Vermeir, L., Pierson, J., Lievens, B., Vanattenhoven, J., \& Jans, G. (2009). Cocreation and user-generated content-elderly people's user requirements. Journal of Computers in Human Behaviour, 25(3), 655678. https://doi.org/10.1016/j.chb.2008.08.012

Kent, M., \& Leaver, T. (2014). An education in Facebook?: Higher education and the world's largest social network. Routledge. https://doi.org/10.4324/9781315883458

Kirschner, P. A., \& Karpinski, A. C. (2010). Facebook and academic performance. Computers in Human Behavior, 26(6), 1237-1245. https://doi.org/10.1016/j.chb.2010.03.024

Kurtz, G. (2014). Integrating a Facebook group and a course website: The effect on participation and perceptions on learning. American Journal of Distance Education, 28(4), 253-263. https://doi.org/ 10.1080/08923647.2014.957952

Labrado, M. G., Labrado, I. K., Rosal, E., Layasan, A., \& Salazar, E. (2020). Initial implementation of printed modular distance learning in the city of Naga-Cebu during COVID-19 pandemic. International Journal of Current Research, 12(10), 14397-14402. https://doi.org/10.24941/ijcr.39921.10.2020

Lonn, S., \& Teasley, S. D. (2009). Saving time or innovating practice: investigating perceptions and uses of Learning Management Systems. Computers \& Education, 53(3), 686-694. https://doi.org/10.1016/j.compedu.2009.04.008

Lydersen, S. (2020). Gjennomsnitt og standardavvik eller median og kvartiler? [Mean and standard deviation or median and quartiles?]. The Journal of the Norwegian Medical Association. https://doi.org/10.4045/tidsskr.20.0032

Mazman, S. G., \& Usluel, Y. K. (2010). Modeling educational usage of Facebook. Computers \& Education 55(2), 444-453. https://doi.org/10.1016/j.compedu.2010.02.008

Meishar-Tal, H., Kurtz, G., \& Pieterse, E. (2012). Facebook groups as LMS: A case study. The International Review of Research in Open and Distance Learning, 13(4), 33-48. https://doi.org/10.19173/ irrodl.v13i4.1294

Menon, V. (2012). Using a Facebook group for interactive clinical learning. International e-Journal of Science, Medicine and Education, 6(1), 21-23.

Moran, M., Seaman, J., Tinti-Kane, H. (2011). Teaching, learning, and sharing: How today's higher education faculty use social media. Babson Survey Research Group. http://files.eric.ed.gov/fulltext/ ED535130.pdf

Niu, L. (2017). Using Facebook for academic purposes: current literature and directions for future research. Journal of Educational Computing Research, 56(8), 1384-1406. https://doi.org/10.1177/ 0735633117745161

O'Brien, S. J. (2011). Facebook \& other internet use \& the academic performance of college students (Doctor of philosophy), Temple University.

Okeniyi, J. O., Okeniyi, E. T., \& Atayero, A. A. (2020). Implementation of data normality testing as a Microsoft Excel ${ }^{\circledR}$ library function by Kolmogorov-Smirnov goodness-of-fit statistics. Proceedings of the Vision, 5261-2578.
Ooi, C. Y., \& Loh, K. Y. (2010). Using online web 2.0 tools to promote innovative learning. In Q. Y. Wang, \& S. C. Kong (Eds), Workshop Proceedings of the 14th Global Conference on Computers in Education (pp. 72-76). National Institute of Education.

Ophus, J. D., \& Abbitt, J. T. (2009). Exploring the potential perceptions of social networking systems in university courses. Journal of Online Learning \& Teaching, 5(4), 639-648.

Özmen, B. \& Atıcı, B. (2014). The effects of social networking sites in distance learning on learners' academic achievements. European Journal of Open, Distance and E-Learning, 17(2), 61-75. https://doi.org/10.2478/eurodl-2014-0019

Özmen, F., Aküzüm, C., Sünkür, M., \& Baysal, N. (2011). Sosyal ağ sitelerinin eğitsel ortamlardaki işlevselliği [Functionality of social networking sites in educational settings]. In Proceeding of the 6th International Advanced Technologies Symposium (IATS'11), (pp. 1618), Elazig, Turkey.

Pai, A., Cole, M., Kovacs, J., Lee, M., Stovall, K., \& McGinnis, G. (2017). As long as you are here, can I interest in you some science? Increasing student engagement by co-opting a social networking site, Facebook for science discussions. Journal of Educational Technology Systems, 46(2), 153-177. https://doi.org/10.1177/ 0047239517729505

Pallant, J. (2007). SPSS Survival Manual: A step by step to data analysis using SPSS for Windows (Version 15). Allen and Unwin.

Pellizzari, P. (2012). Facebook as an academic learning platform: A case study in mathematics. University Ca' Foscari of Venice, Dept. of Economics Research Paper Series No. 01/WP/2012. https://doi.org/10.2139/ssrn.2016139

Ractham, P., \& Firpo, D. (2011). Using social networking technology to enhance learning in higher education: A case study using Facebook. In Proceedings of the 44th Hawaii International Conference on System Sciences. https://doi.org/10.1109/HICSS.2011.479

Samani, E., \& Noordin, N (2020). Getting connected with Facebook Messenger: Exploring meaningful interactions through online chats. Journal of Modern Research in English Language Studies, 7(3), 23 44. https://doi.org/10.30479/jmrels.2020.11985.1492

Soong, T. T. (2004). Fundamentals of probability and statistics for engineers. John Wiley \& Sons, Ltd.

Tananuraksakul, N. (2018). Facebook Messenger as the medium of academic consultation and the message in a Thai context. In $e^{-}$ proceedings International Conference on Communication $\&$ Media, 1819 October 2018. https://www.academia.edu/40623176/Facebook _Messenger_as_the_medium_of_academic_consultation_and_the_ message_in_a_Thai_context

Thoms, B., \& Eryilmaz, E. (2014). How media choice affects learner interactions in distance learning classes. Computers \& Education, 75, 112-126. https://doi.org/10.1016/j.compedu.2014.02.002

Towner, T. L., \& Munoz, C. L. (2011). Facebook and education: a classroom connection? In Educating educators with social media. Emerald Group Publishing Limited. https://doi.org/10.1108/S2044-9968(2011)0000001005

Vodanovich, S., Sundaram, D., \& Myers, M. (2010). Digital natives and ubiquitous information systems. Information Systems Research, 21(4), 711-723. https://doi.org/10.1287/isre.1100.0324 
Wang, Q., Woo, H., Quek, C., Yang, Y., \& Liu, M. (2011). Using the Facebook group as a learning management system: An exploratory study. British Journal of Educational Technology, 43(3), 1-11. https://doi.org/10.1111/j.1467-8535.2011.01195.x

West, R. E., Waddoups, G., \& Graham, C. R. (2007). Understanding the experiences of instructors as they adopt a course management system. Educational Technology Research \& Development, 55(1), 1-26. https://doi.org/10.1007/s11423-006-9018-1
Yuen, S., \& Yuen, P. (2008). Social networks in education. In G. Richards (Eds.), In Proceedings of world conference on e-learning in corporate, government, healthcare, and higher education (pp. 14081412). AACE. 